\title{
Giant carbon solubility in Au nanoparticles
}

\author{
Eli A. Sutter $\cdot$ Peter W. Sutter
}

Received: 24 March 2011/Accepted: 25 May 2011/Published online: 10 June 2011

(C) Springer Science+Business Media, LLC 2011

\begin{abstract}
Variable temperature transmission electron microscopy of individual $5 \mathrm{~nm}$ Au nanoparticles shows a striking increase in the particle size on raising the temperature from room temperature to $500{ }^{\circ} \mathrm{C}$ in the presence of carbon from amorphous carbon support. Using the assembly of ordered graphene shells on the surface of individual nanoparticles at elevated temperatures-and the high pressures induced by such shells-as an experimental tool to study the origins of this swelling, we find that the volume increase is associated with the uptake of carbon to concentrations exceeding the bulk solubility by more than four orders of magnitude. The formation of stable metalcarbon nanostructures that have no bulk equivalent may have important implications on the functional properties of metal nanoparticles.
\end{abstract}

The interaction of carbon with transition metals is key to processes for synthesizing the known $s p^{2}$ bonded carbon allotropes-fullerenes, nanotubes, and graphene-all of which are materials showing extraordinary properties and enormous potential for applications.

Graphene, a planar two-dimensional honeycomb lattice of $s p^{2}$ bonded carbon atoms [1], holds the promise for large-scale applications in micro- and optoelectronics [2-4] and sensing [5], owing to characteristics such as a very high carrier mobility [2] and long ballistic mean free path

Electronic supplementary material The online version of this article (doi:10.1007/s10853-011-5663-9) contains supplementary material, which is available to authorized users.

E. A. Sutter $(\bowtie) \cdot$ P. W. Sutter

Center for Functional Nanomaterials, Brookhaven National

Laboratory, Upton, NY 11973, USA

e-mail: esutter@bnl.gov at room temperature combined [3] with very low optical absorption, and the possibility of opening a variable bandgap by confinement in nanoscale ribbons [6]. One of the promising uses of curved multiwalled fullerenes involves encapsulating other materials, most notably metal nanoparticles. Fullerene shells on metal nanoparticles (magnetic $\mathrm{Ni}, \mathrm{Fe}, \mathrm{Co}$ and their alloys, as well as $\mathrm{Cu}, \mathrm{Al}, \mathrm{La}, \mathrm{Au}, \mathrm{Ag}$, etc.) generally limit oxidation [7], improve stability in air and corrosive liquids [8], provide biocompatibility and open applications such as medical imaging [9], targeted drug delivery [10-13]. In addition, fullerene shells can protect nanoparticles against agglomeration-thus maintaining their size distribution during processing [14] and preserving their strongly size-dependent properties [15] and enhance the magnetic properties of nanoparticle arrays by reducing magnetic interparticle interactions.

Typically, transition metals catalytically dissociate hydrocarbons at their surfaces to set free carbon adatoms, which can be absorbed into the bulk at high temperature and segregate to the surface on subsequent cooling to form $s p^{2}$-bonded structures. Planar graphene is synthesized by this process on bulk crystals or thin films of transition metals, such as Ru [16-18], Pt [19], Ir [20], and Ni [21], which can take up carbon into interstitial sites with solubilities up to a few atomic percent. Carbon nanostructures, such as fullerenes [22-25] are synthesized over transition metal ( $\mathrm{Fe}, \mathrm{Ni}, \mathrm{Co}$ ) nanoparticles, using the same steps of hydrocarbon dissociation, carbon intake into interstitial sites, and precipitation. It is generally assumed that the uptake of carbon in metal nanoparticles involves interstitial sites, similar to the bulk, but the stable concentrations (i.e., the carbon solubility) may be different at the nanoscale. The high surface-to-volume ratio of nanoparticles has been predicted to cause a significant increase of the solubility [26-33]. However, lattice relaxation in very small particles 
Fig. 1 Overview TEM images characteristic of the $\mathrm{Au}$ nanoparticles at a room temperature and $\mathbf{b} 440{ }^{\circ} \mathrm{C}$ c Distribution of nanoparticle sizes at room temperature (top) and $440{ }^{\circ} \mathrm{C}$ (bottom). Larger nanoparticle arrays are shown in the Supplementary online material, Fig. S1
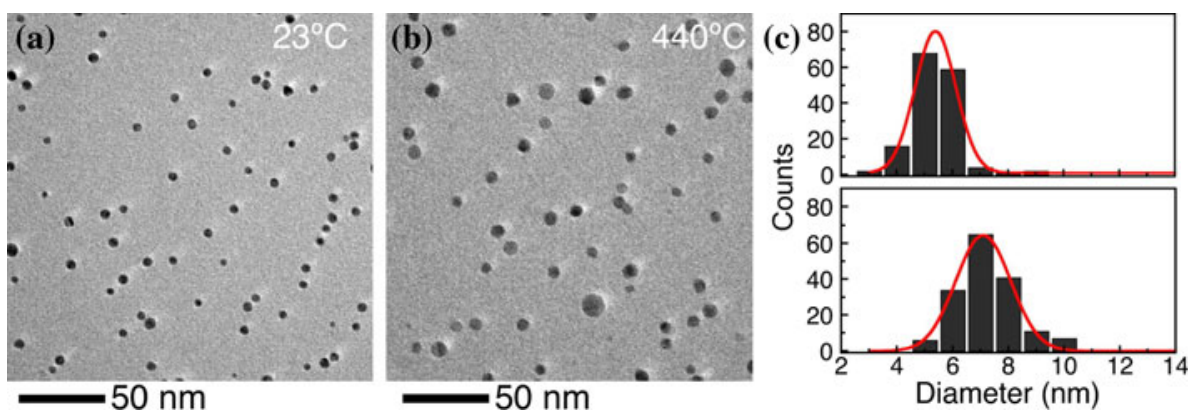

can also reduce the stable interstitial carbon concentration [34]. There is a growing consensus that solid solutions as well as the phase behavior of alloys at the nanoscale remain poorly understood [30, 31, 35].

Metal nanoparticles could give rise to pathways of carbon incorporation that have no bulk equivalent. A key difference to a bulk metal single crystal is the possibility of facile mass transport between the interior and the surface, enabling the transfer of host atoms by diffusion to surface site [36]. At elevated temperatures, this exchange may allow for the formation of stable mixed metal-carbon nanoparticles that have a reduced density of host metal atoms but still retain the bulk crystal structure of the host. For example, a drastic reduction in the vacancy formation energy and in the activation energy of diffusion, shown consistently in calculations for small particles [36-42], could give rise to a net outdiffusion of host atoms and lead to large concentrations of vacancies, which in combination with a solute, such as carbon, could form vacancy-interstitial complexes that may be stable at the nanoscale. If such effects indeed occur, they may be quite prevalent in transition metal particles used for the synthesis of nanostructured carbon allotropes or in catalytic chemistry. However, direct microscopic observations of the carbon uptake of individual metal nanoparticles during annealing, necessary to establish the existence of such phenomena, have not been performed to date.

Here, we use in situ high-resolution transmission electron microscopy (TEM) to investigate the interaction of transition metal nanoparticles with carbon at elevated temperatures. Our experiments were specifically designed to follow the transformation of individual nanoparticles during exposure to $\mathrm{C}$ from an amorphous $\mathrm{C}$ support over a wide range of temperatures. Gold nanoparticles were chosen for their chemical inertness and stability at room temperature in air, and because Au has negligible solubility of interstitial $\mathrm{C}$ in the bulk. Our high-resolution TEM observations show a striking increase in the size of $\mathrm{Au}$ nanoparticles - a near-doubling of their volume-on raising their temperature from room temperature to 400-500 ${ }^{\circ} \mathrm{C}$ in the presence of $\mathrm{C}$. We use the assembly of ordered graphene shells on the surface of the nanoparticles at high temperatures [14, 43]-and the high pressures induced by such shells [14, 43, 44]-as an experimental tool to study the origins of this swelling of the Au particles. A quantitative analysis relates the volume increase to a cooperative effect involving the redistribution of $\mathrm{Au}$ atoms to the surface, formation of vacancies, and a concurrent uptake of $\mathrm{C}$ to concentrations exceeding the bulk solubility by several orders of magnitude. Our results demonstrate that such cooperative effects, which can be all but neglected in bulk solids, may cause unexpected phenomena such as very high solute solubilities in nanoparticles.

TEM images characteristic of the Au nanoparticles in the temperature range between room temperature and $500{ }^{\circ} \mathrm{C}$ are shown in Fig. 1. The images are representative of an entire ensemble of nanoparticles, i.e., obtained on different groups of particles, and were taken before and after heating without electron beam exposure during heating. Images of the annealing-induced transformations in significantly larger nanoparticle arrays and associated explanations are given in the Supplementary online material, Fig. S1. Special care was taken to produce sparse ensembles with well-separated particles to limit their interactions via well-known phenomena, such as Ostwald ripening [45] or thermally driven sintering or coalescence $[46,47]$. Figure 1a shows a representative group of nanoparticles at room temperature. The majority of the particles have diameters between 4.5 and $6.5 \mathrm{~nm}$; the mean diameter is $5.4 \pm 0.5 \mathrm{~nm}$. The particle size distribution shifts significantly toward larger sizes on heating to $440{ }^{\circ} \mathrm{C}$ (over $\sim 20 \mathrm{~min}$ ). The majority of the nanoparticles now have diameters between 6.0 and $8.5 \mathrm{~nm}$; the mean diameter is $7.1 \pm 1.2 \mathrm{~nm}$.

To explore if the observed size increases are due to nanoparticle interactions such as ripening or coalescence, or instead result from the exchange of material between individual, isolated particles and the $\mathrm{C}$ support, we have tracked and imaged a large number of conspicuous small groups of $\mathrm{Au}$ nanoparticles during the entire heating process. We increased the temperature stepwise from room temperature, translating the sample in all three spatial directions to maintain the same group of particles in the field of view and in focus up to temperatures above $400{ }^{\circ} \mathrm{C}$. 
One of the groups is shown in Fig. 2a. Its particle spacing is $30-50 \mathrm{~nm}$, with the group separated by hundreds of nanometers from any other Au particles. A comparison of TEM images at low and high temperatures is shown in Fig. 2b-e, respectively. It is evident that all particles in this representative group experienced an overall increase in size while, importantly, the number of particles and location of each particle have remained unchanged. Ripening, i.e., the growth of large particles at the expense of neighboring smaller particles with higher curvature, would not explain the growth of all particles in the isolated group shown in Fig. 2. We have carried out additional analysis to rule out ripening as the cause for the observed volume increases of small, C-supported $\mathrm{Au}$ nanoparticles (see Supplementary Fig. S2, for discussion). Given that the number and arrangement of the particles in Fig. 2 remain unchanged, coalescence can likewise be ruled out as the cause for the particles size increase in sparse ensembles. In identical experiments with densely spaced nanoparticles, however, coalescence was observed for sufficiently small separations (Supplementary Fig. S2) [14]. Our variable temperature microscopy on sparse nanoparticle ensembles clearly demonstrates that the increase in particle size has an origin different from coalescence and ripening.

To rule out simple geometric effects, e.g., due to a change from a spherical shape at room temperature to a non-spherical shape that might give rise to a larger projected footprint in TEM, we have performed tilt series in annular dark field scanning TEM (DF-STEM) on nanoparticles in their "expanded" state. Selected DF-STEM images from a tilt series acquired on a group of Au nanoparticles after heating to $450{ }^{\circ} \mathrm{C}$ are shown in Fig. 3a-c (for a complete tilt series, see the Online supplement, Movie S1). Analysis of the STEM images (Fig. 3d) shows that the relation between the $x$ - and $y$-projections of the Au nanoparticles is preserved in the entire tilt series, i.e., their shape never deviates significantly from spherical.

Selected area electron diffraction (SAED) provides further information on changes accompanying the large volume increases during heating. SAED patterns of a group of Au nanoparticles at room temperature and after heating to $460{ }^{\circ} \mathrm{C}$ are shown in Fig. 4. The diffraction pattern from the group of randomly oriented nanoparticles consists of spots that lie on diffuse rings and originate from the facecentered cubic (fcc) Au structure. The circles correspond to the spacing of the $(h k l)$ lattice planes, as indexed in the ring diffraction pattern in Fig. 4a, with spacing $d_{h k l}$ initially close to that of bulk fcc gold (see below). At room temperature, the $d_{111}$ lattice spacing in the $5 \mathrm{~nm}$ nanoparticles is slightly higher $(2.41 \pm 0.09 \AA)$ than that in the larger, bulk-like reference particles $(2.35 \pm 0.05 \AA)$. On heating to $460{ }^{\circ} \mathrm{C}$, the diffraction spots of the $5 \mathrm{~nm}$ particles lie on
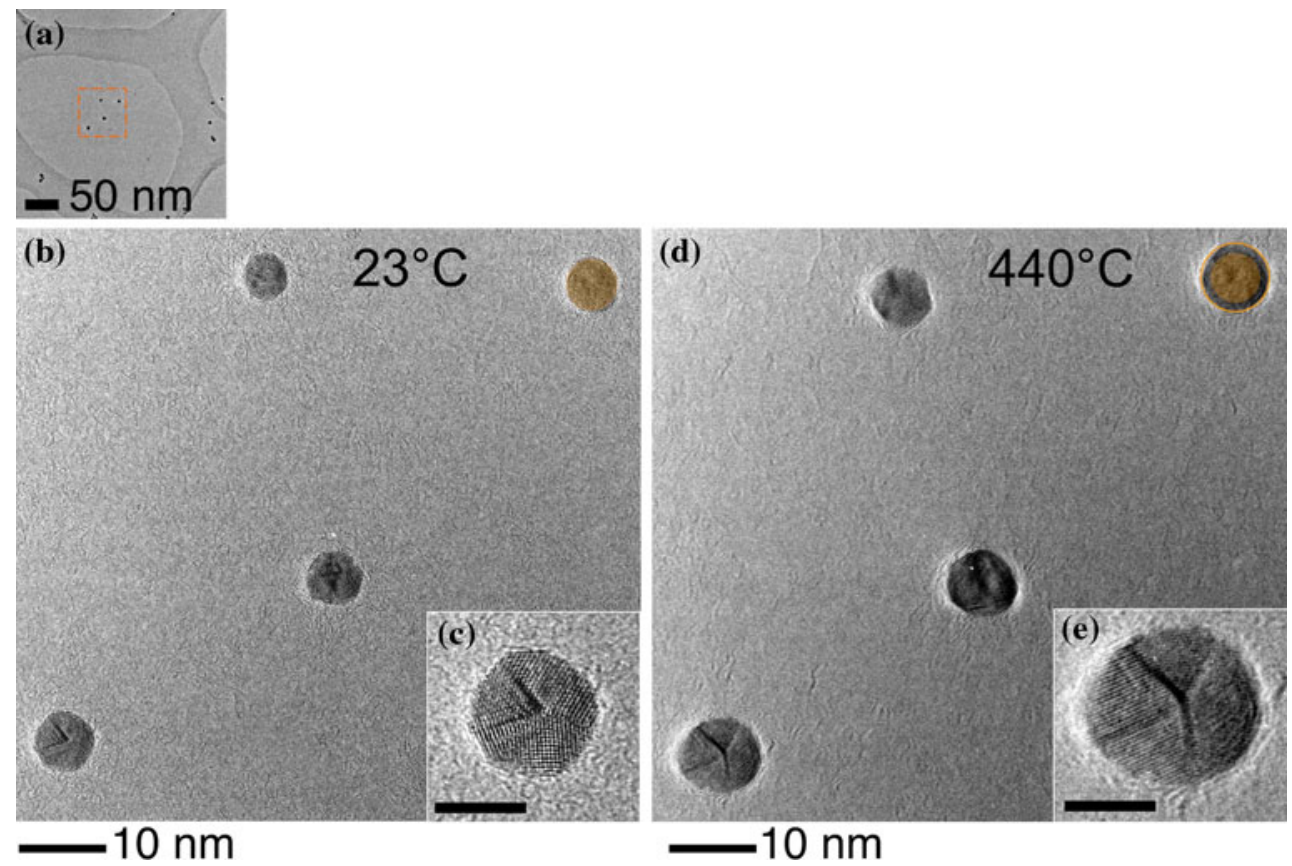

Fig. 2 TEM images of the same group of $\mathrm{Au}$ nanoparticles at a-c room temperature and $\mathbf{d}-\mathbf{e} 440{ }^{\circ} \mathrm{C}$. a An overview TEM image showing that the group of $4 \mathrm{Au}$ nanoparticles is part of an extremely sparse array, hundreds of nanometers away from other Au particles. b High-resolution TEM image of the $\mathrm{Au}$ nanoparticles at room temperature, interparticle distance $30-50 \mathrm{~nm}$. c Detail of the lower

left particle, scale marker $-5 \mathrm{~nm}$. d High-resolution TEM image of the $\mathrm{Au}$ nanoparticles from b at $440{ }^{\circ} \mathrm{C}$. e Detail of the lower left particle (same as in c), scale marker- $5 \mathrm{~nm}$. The nanoparticle in the right corner in $\mathbf{d}$ is superimposed with a colored disc of the size of the same particle at room temperature 
Fig. 3 a-c Selected DF-STEM images from tilt series (tilt axis parallel to $y$-axis, complete tilt series shown in Supplementary online material, Movie S1) acquired on a group of $\mathrm{Au}$ nanoparticles after heating to $450{ }^{\circ} \mathrm{C}$. d Particles height-towidth ratio, extracted from the tilted images at different tilt angles between $-65^{\circ}$ and $45^{\circ}$

Fig. 4 Selected area electron diffraction pattern of group of $5 \mathrm{~nm} \mathrm{Au} \mathrm{nanoparticles}$ nanoparticles at a room temperature and b $460{ }^{\circ} \mathrm{C}$. The ring diffraction patterns of $\mathrm{Au}$ with fcc structure are superimposed. The Gaussian broadening due to the finite particle size $(5 \mathrm{~nm})$ is shown as well. c Comparison of the diffraction patterns in the initial and final (expanded) state. d Diffraction pattern after cooling to room temperature
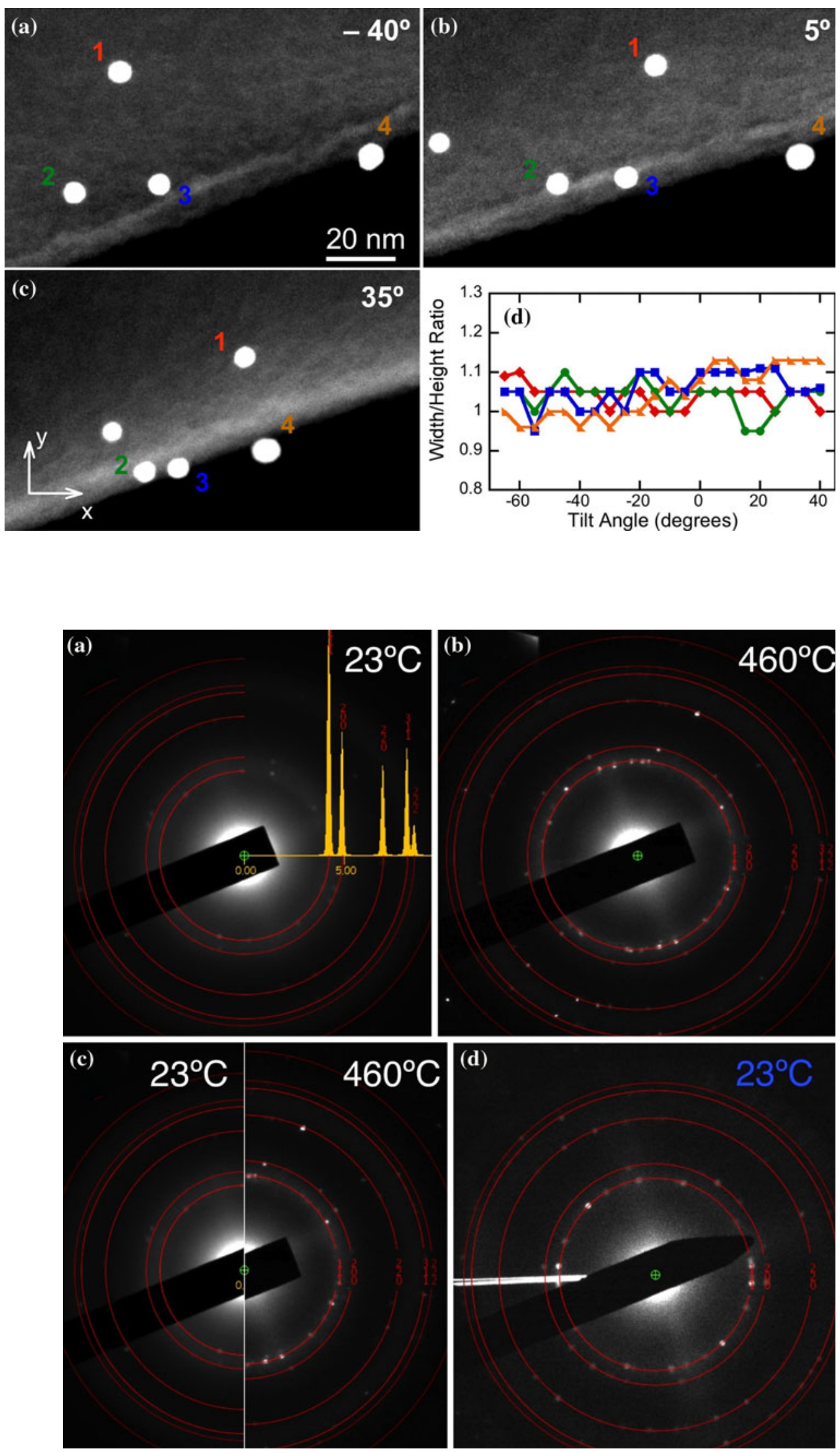
Fig. 5 TEM images of a group of $20 \mathrm{~nm} \mathrm{Au}$ nanoparticles at a room temperature and b $460{ }^{\circ} \mathrm{C}$. The insets show higher-magnification images of one of the particles in the group. c-d Corresponding selected area electron diffraction pattern of the group of nanoparticles at room temperature and $460{ }^{\circ} \mathrm{C}$, respectively. Ring diffraction patterns of fcc Au are shown as well
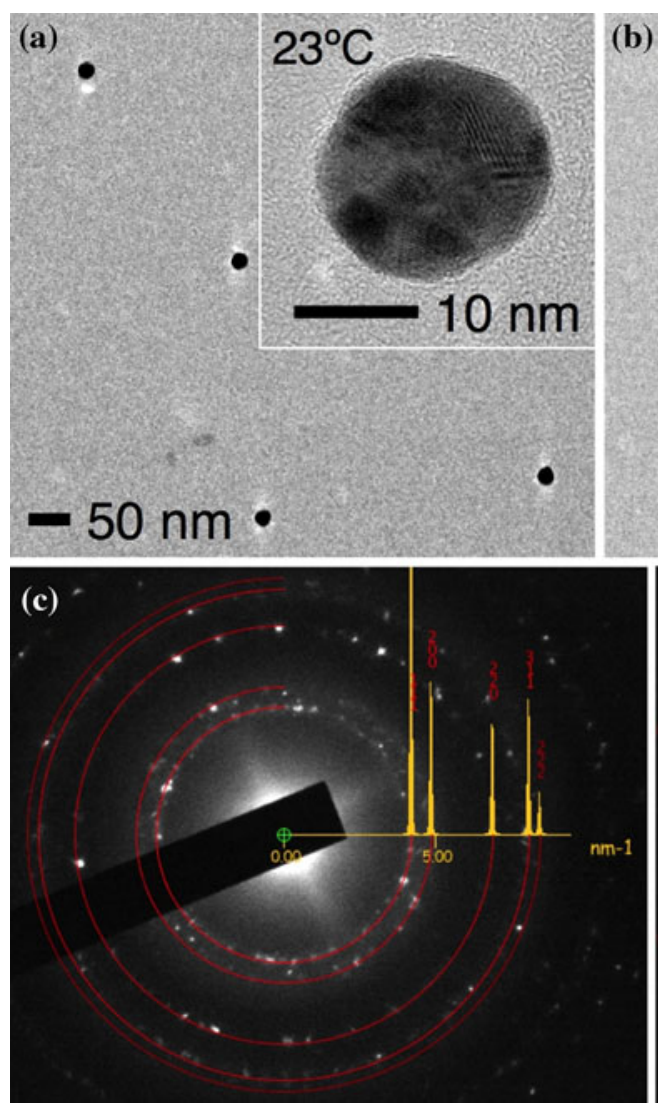

(b) $\quad 460^{\circ} \mathrm{C}$
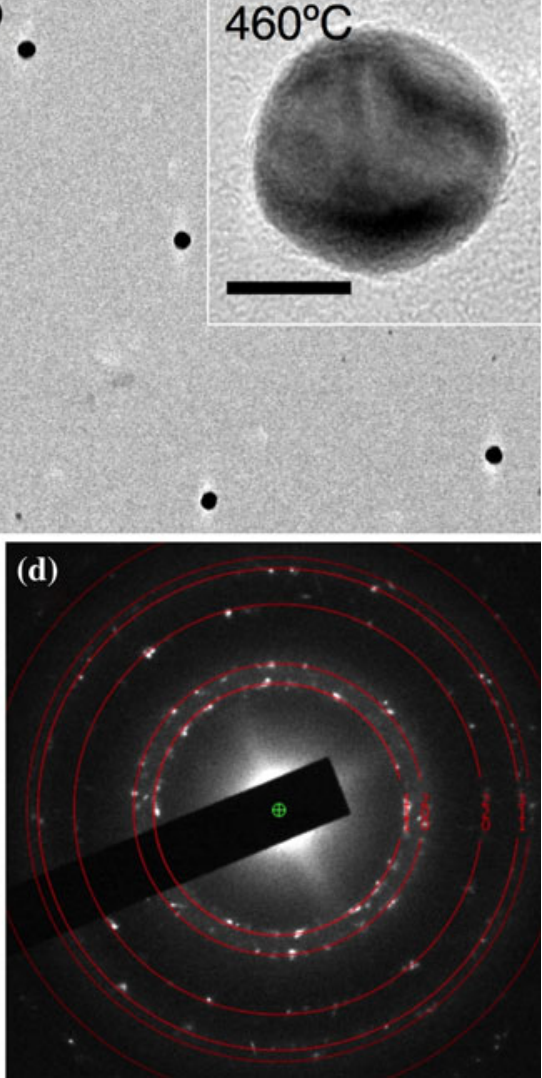

rings that can be systematically indexed to the fcc gold structure, however, the diffraction rings increase uniformly in size (Fig. 4b), indicating a contraction of the lattice. The direct comparison in Fig. $4 \mathrm{c}$ clearly illustrates this change in the diffraction pattern. The $d_{111}$ lattice spacing deduced from Fig. $4 \mathrm{~b}$ is reduced by about $11 \%(2.16 \pm 0.09 \AA)$ concomitant with the volume increase of the C-supported particles at high temperature. In contrast, for bulk $\mathrm{Au}$ one would expect a thermal expansion of the lattice by about $0.5 \%$ for the same temperature increase (linear thermal expansion coefficient, $14.2 \times 10^{-6} \mathrm{~K}^{-1}$ ). Figure $4 \mathrm{~d}$ shows that after cooling down to room temperature the particles preserve the reduced lattice spacing. To explore the behavior of larger, more bulk-like Au particles under the same conditions, i.e., supported by $\mathrm{C}$ and annealed from room temperature to $460{ }^{\circ} \mathrm{C}$, we have performed control experiments with $20 \mathrm{~nm} \mathrm{Au}$ nanoparticles. The larger particles still show a sizable increase in volume, about $20 \%$, on annealing (Fig. 5a, b), but the concomitant change in their lattice constants is small and remains within the limits expected for a simple thermal expansion effect (Fig. 5c, d).

For the system of $\mathrm{Au}$ nanoparticles on amorphous $\mathrm{C}$ support we have shown previously that at elevated temperatures $\mathrm{C}$ rapidly diffuses onto the Au particles, and can cause the assembly of small graphene fragments around them [14]. The present investigation shows that this process is preceded by a marked increase in the particle size. Given that the only major atomic species present are $\mathrm{Au}$ and $\mathrm{C}$, it is natural to assume that this increase in size is due to interactions with the $\mathrm{C}$ reservoir. Control experiments with identical particles dispersed on C-free supports confirm this assumption. During annealing of $5 \mathrm{~nm}$ Au nanoparticles on a thin $\mathrm{SiO}_{x}$ support, for example, no change in the size distribution is observed (Supplementary Fig. S3). Addition of 1-2 nm amorphous carbon onto the $\mathrm{SiO}_{x}$ support causes an increase in the size of the particles (Supplementary Fig. S4), i.e., the presence of a $\mathrm{C}$ reservoir is required to drive the dramatic increase in the particle sizes on heating. We conclude that the expansion involves an uptake of $C$ into the interior of the particles. Simultaneously, $\mathrm{Au}$ atoms from the interior appear to migrate to the surface, thus giving rise to the observed increase in the overall particle volume. The magnitude of the effect-a near-doubling of the volume-is highly unusual, especially since the solubility of $\mathrm{C}$ in bulk $\mathrm{Au}$ is extremely low $\left(<0.00004-0.004\right.$ at $\%$ at $\left.530{ }^{\circ} \mathrm{C}[48,49]\right)$. If $\mathrm{C}$ uptake plays a role here, the solubility of $\mathrm{C}$ in nanometer-sized $\mathrm{Au}$ crystals must be significantly enhanced. Such a size effect may not be entirely unexpected since the large surface-tovolume ratio of nanoclusters is known to relax solubility constraints in binary alloy systems [30-33], and also 

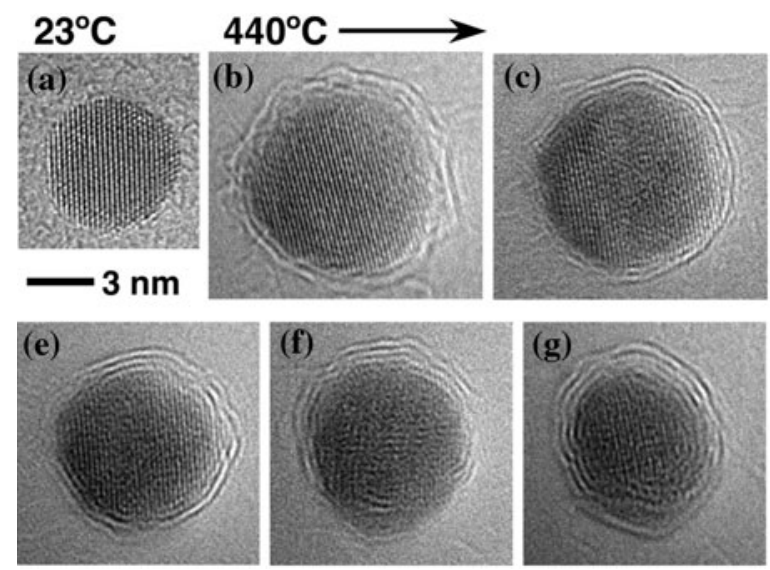

Fig. 6 Sequence of high-resolution TEM images showing an isolated Au nanoparticle $\mathbf{a}$ at room temperature, $\mathbf{b}$ with larger diameter and graphene fragments on the surface at high temperature, c-e its

affects other thermodynamic and kinetic properties, such as the cohesive energy and melting temperature $[50,51]$ as well as the crystallization pathway [44].

A direct demonstration of significant quantities of dissolved C in the "expanded" $\mathrm{Au}$ nanoparticles at high temperature, and possibly even quantitative information on the amount of dissolved $\mathrm{C}$, could be obtained if $\mathrm{C}$ precipitation or surface segregation could be triggered at elevated temperatures, e.g., by destabilizing the Au nanoparticles in their "expanded" state. We explored if the application of high hydrostatic pressures could have this effect, as high pressures effectively destabilize both $\mathrm{Au}$ vacancies [52] and $C$ interstitials [35, 53]. High-pressure experiments are indeed feasible in the TEM if ordered graphene shells, assembled at elevated temperature under intense electron irradiation, are used to generate pressure on the nanoparticles [14, 43, 44].

The sequence of TEM images in Fig. 6 documents the assembly of an ordered C-shell around an isolated $\mathrm{Au}$ nanoparticle, and the further evolution of the core-shell structure. The high-resolution image in Fig. 6a shows an fcc nanoparticle with an initial diameter of $5.9 \mathrm{~nm}$ at room temperature. The observed lattice fringes are consistent with the spacing of the (111) planes in bulk Au. On heating to $440{ }^{\circ} \mathrm{C}$ (Fig. 6b) the nanoparticle increases in size to a diameter of about $8.2 \mathrm{~nm}$, i.e., shows the effects discussed above. Small graphene fragments assemble on its surface and under more intense electron irradiation [14, 43, 54] a complete encapsulation in an ordered C-shell is achieved (Fig. 6c). The images in Fig. 6c-h show a time-lapse sequence of the further evolution of this C-encapsulated nanoparticle. While the volume of the $\mathrm{Au}$ particle increased substantially during annealing, the formation of an ordered graphene shell reverses this trend. The size of the encapsulated particle decreases visibly with elapsed time between Fig. $6 \mathrm{c}$ and g, over the course of about $10 \mathrm{~s}$.
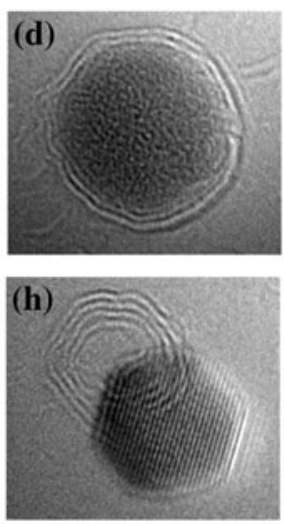

(i)

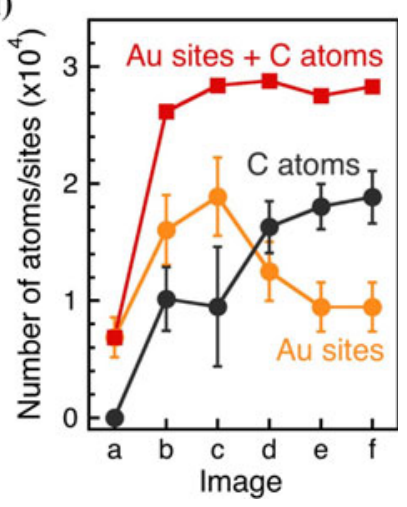

encapsulation in an ordered carbon shell at $440{ }^{\circ} \mathrm{C}$ and $\mathbf{f}-\mathbf{h}$ the displacement of the particle from the shell. i Sequence of measurements of the volume of the Au core and the C-shell for images $\mathbf{a}-\mathbf{h}$

Simultaneously, the number of $\mathrm{C}$ layers in the shell increases. Eventually, the $\mathrm{C}$-shell ruptures and the $\mathrm{Au}$ particle is expelled from the shell $[14,43]$ (Fig. 6g, h). The final configuration is a faceted fcc Au nanoparticle alongside the empty, nearly spherical multilayer C-shell. Importantly, the expelled Au particle in its final state is much smaller than the same particle in its "expanded" state at high temperature prior to the assembly of the C-shell, and still somewhat larger than its initial size at room temperature prior to annealing.

A sequence of measurements of the volume of the $\mathrm{Au}$-rich core can be used to assess the redistribution of $\mathrm{Au}$ atoms in the particle. Given that the total number of $\mathrm{Au}$ atoms in the particle remains unchanged, any increase in the observed Au-rich volume implies the displacement of $\mathrm{Au}$ atoms from interior sites to the surface. This process increases the overall number of Au lattice sites, but some of these sites necessarily remain vacant or become populated with a species other than Au. Conversely, a shrinking of the particle implies the redistribution of $\mathrm{Au}$ atoms from the surface to fill vacant interior sites. The redistribution of $\mathrm{C}$ atoms can be tracked in an analogous way by observing the $\mathrm{C}$-shell enclosing the nanoparticle. Once the surface is terminated by $s p^{2}$ bonded $\mathrm{C}$, additional $\mathrm{C}$ layers are added from the inside, i.e., an increase in number of $\mathrm{C}$ atoms in the shell corresponds to a loss of the same amount of $\mathrm{C}$ from the encapsulated particle.

Figure 6i shows such measurements for the image sequence of Fig. 6a-h, i.e., during the buildup of hydrostatic pressure by the $\mathrm{C}$-shell. The number of $\mathrm{Au}$ sites is calculated from the measured particle volume, approximated by a sphere and assuming the density of bulk Au. The number of $\mathrm{C}$ atoms in the shell is determined from the area of each $\mathrm{C}$ layer and the area density of $\mathrm{C}$ atoms in a two-dimensional graphene sheet. From a maximum particle volume (number of Au sites) in Fig. 6c, the pressure generated 
by the $\mathrm{C}$-shell causes a continuous reduction of the particle volume, implying the diffusion of $\mathrm{Au}$ atoms from the surface back into bulk sites. Simultaneously, the number of $\mathrm{C}$ atoms in the shell increases by the same amount, implying a reverse migration of $\mathrm{C}$ atoms from bulk sites to the surface, followed by incorporation into the C-shell. From the one-to-one correspondence between the influx of $\mathrm{Au}$ atoms and loss of $\mathrm{C}$ atoms in the particle interior, shown in Fig. 6i, we can draw important conclusions about the $\mathrm{Au}$ particles in their "expanded" state. Clearly, reaching the "expanded" state involves the creation of a large population of unoccupied $\mathrm{Au}$ sites, i.e., vacancies. Applying high pressures destabilizes these vacancies, and drives the re-population of these sites by $\mathrm{Au}$ atoms. In addition, our measurements demonstrate directly that each of these vacancies is, on average, associated with one $\mathrm{C}$ atom. Hence, an extensive uptake of $\mathrm{C}$ accompanies the initial volume increases of the particles during annealing, and applied pressure drives the precipitation and surface segregation of this "dissolved" C.

Before discussing possible mechanisms of the large $\mathrm{C}$ solubility in nanoscale Au particles, we briefly summarize our main experimental findings. In the presence of $\mathrm{C}$ from an amorphous $\mathrm{C}$ support, $5 \mathrm{~nm}$ Au nanoparticles grow to about twice their original volume on annealing from room temperature to $440{ }^{\circ} \mathrm{C}$. This expansion occurs without a change of the lattice structure, but is accompanied by a decrease in the lattice parameter by about $11 \%$. Under application of high pressures the expansion is reversed, and $\mathrm{C}$ precipitates at the particle surface. The uptake of $\mathrm{C}$ during the volume expansion of the nanoparticles corresponds to the number of vacancies created by displacing $\mathrm{Au}$ atoms from the interior to the surface. From these experimental findings, we can deduce a likely scenario for the incorporation of $\mathrm{C}$ in $\mathrm{Au}$ nanoparticles. In bulk fcc metals, the incorporation of $\mathrm{C}$ into $0,0,1 / 2$ interstitial sites is limited by lattice strain due to the size of the solute atom. In a nanoparticle, such constraints may be lifted to some extent because the proximity of the free surface allows lattice rearrangement and elastic relaxation. Hence, a larger solubility of interstitial $\mathrm{C}$ might be expected. Our observations, however, suggest a different mechanism accommodating much larger amounts of $\mathrm{C}$ during annealing. The net migration of large amounts of $\mathrm{Au}$ from the particle interior to the surface, and uptake of the equivalent number of $\mathrm{C}$ atoms suggests the formation of a vacancy-solute complex, pairing each $\mathrm{C}$ atom with one vacancy. The $\mathrm{C}$ atom can either occupy an interstitial site, or move to the substitutional site instead. Both types of complexes would be consistent with the lattice contraction observed by electron diffraction. The extremely high concentration of these complexes in small $(5 \mathrm{~nm})$ Au nanoparticles suggests a very low formation energy. In fact, the concentration is approaching the limit (50 at $\%)$ expected for an uptake driven purely by configurational entropy for zero energy of formation of the vacancy-solute complex. For the same conditions, the volume of larger $(20 \mathrm{~nm}) \mathrm{Au}$ particles increases by only about $20 \%$, and the lattice contraction is no longer detectable. This suggests a pronounced stabilization of the vacancy-solute complex in $5 \mathrm{~nm}$ particles, but a finite energy of formation in $20 \mathrm{~nm}$ particles.

The observed dramatic increase in carbon solubility is important since nanoparticles containing such large amounts of carbon will likely have properties-electronic, optical, catalytic, etc.- - that differ significantly from those of their pure metallic counterparts. Our observation that the particles remain carbon rich on cooling to room temperature opens up the possibility of studying these properties. The very high solubility of carbon in Au nanoparticles established here is important for understanding the initial stages of the formation of ordered graphene shells on transition metal nanoparticles, and emphasizes the need to consider the facile uptake, storage, and release of carbon in such growth processes. The stabilization of small particles with very high carbon content may also have important ramifications for catalysis by transition metal and noble metal nanoparticles. For catalysts used in hydrocarbon reforming, for instance, it is well-known that the exposure to atomic carbon at elevated temperature can lead to the deactivation by coking, i.e., the formation of graphitic and other carbon deposits on the surface. Our observations point to an additional possible effect of free carbon on nanoparticle catalysts, the uptake of $\mathrm{C}$ to very high concentrations well beyond established solid solubility limits in the bulk, which may modify the activity or selectivity of a nanoparticle catalyst — without necessarily causing deactivation - by changing its composition, coordination, strain, and electronic structure. Recently, there has been increased awareness of the role of subsurface solutes in bulk-like model catalysts ( $\mathrm{Pd}, \mathrm{Cu}$, etc.) by recognizing, for example, that carbon in the bulk and the subsurface, usually considered "frozen," actually changes the structure of the surface and even participates in heterogeneous catalysis [55-58]. Our findings suggest that similar effects may be even more pronounced in nanoparticles, capable of forming mixed metal-carbon structures that have no bulk equivalent and give rise to extremely high solute solubilities.

\section{Methods}

The in situ experiments were carried out in JEOL JEM 3000F and FEI Titan 80-300 TEM with a $\mathrm{C}_{\mathrm{s}}$-corrector, equipped with a Gatan high temperature sample holder. The specific system considered here are Au particles with $\sim 5 \mathrm{~nm}$ nominal initial diameter (British BioCell International) dispersed on amorphous $\mathrm{C}$ films supported by 
standard $\mathrm{Cu}, \mathrm{Au}$, and $\mathrm{Ni}$ grids. The experiments were carried out in the temperature range between room temperature and $500{ }^{\circ} \mathrm{C}$ at pressures below $9 \times 10^{-8}$ Torr, and at electron irradiation intensities below $2 \mathrm{~A} / \mathrm{cm}^{2}$. Brief high intensity $\left(50 \mathrm{~A} / \mathrm{cm}^{2}\right)$ exposure above $400{ }^{\circ} \mathrm{C}$ was used to achieve the transformation of small graphene fragments on the surface of the nanoparticles into ordered layers according to the procedure described in references [14] and [15]. TEM observation and high-resolution TEM imaging, on the other hand, was performed with low electron intensity to prevent any uncontrolled structural changes of the nanoparticles.

Acknowledgements The authors would like to thank Dr. J. Ciston for help with acquiring the STEM tilt series. This work was performed at the Center for Functional Nanomaterials, Brookhaven National Laboratory, which is supported by the U.S. Department of Energy, Office of Basic Energy Sciences, under Contract No. DE-AC02-98CH10886.

\section{References}

1. Geim AK, Novoselov KS (2007) Nat Mater 6(3):183

2. Novoselov KS, Geim AK, Morozov SV, Jiang D, Zhang Y, Dubonos SV, Grigorieva IV, Firsov AA (2004) Science 306(5296):666

3. Berger C, Song ZM, Li XB, Wu XS, Brown N, Naud C, Mayou D, Li TB, Hass J, Marchenkov AN, Conrad EH, First PN, de Heer WA (2006) Science 312(5777): 1191

4. Avouris P, Chen ZH, Perebeinos V (2007) Nat Nanotechnol 2(10):605

5. Schedin F, Geim AK, Morozov SV, Hill EW, Blake P, Katsnelson MI, Novoselov KS (2007) Nat Mater 6(9):652

6. Chen ZH, Lin YM, Rooks MJ, Avouris P (2007) Physica E 40(2):228

7. Ruoff RS, Lorents DC, Chan B, Malhotra R, Subramoney S (1993) Science 259(5093):346

8. Dravid VP, Host JJ, Teng MH, Elliot B, Hwang JH, Johnson DL, Mason TO, Weertman JR (1995) Nature 374(6523):602

9. Kim DK, Zhang Y, Kehr J, Klason T, Bjelke B, Muhammed M (2001) J Magn Magn Mater 225(1-2):256

10. Wozniak MJ, Wozniak P, Bystrzejewski M, Cudzilo S, Huczko A, Jelen P, Kaszuwara W, Kozubowski JA, Lange H, Leonowicz M, Lewandowska-Szumiel M (2006) J Alloys Compd 423(1-2):87

11. Hafeli UO (2004) Int J Pharm 277(1-2):19

12. Sun SH, Murray CB, Weller D, Folks L, Moser A (2000) Science 287(5460): 1989

13. Hyeon $\mathrm{T}$ (2003) Chem Commun 8:927

14. Sutter E, Sutter P, Zhu YM (2005) Nano Lett 5(10):2092

15. Bonard JM, Seraphin S, Wegrowe JE, Jiao J, Chatelain A (2001) Chem Phys Lett 343(3-4):251

16. Sutter PW, Flege JI, Sutter EA (2008) Nat Mater 7(5):406

17. Sutter E, Acharya DP, Sadowski JT, Sutter P (2009) Appl Phys Lett 94(13):133101

18. Sutter PW, Albrecht PM, Sutter EA (2010) Appl Phys Lett 97(21):21301

19. Sutter P, Sadowski JT, Sutter E (2009) Phys Rev B 80(24): 245411
20. N'Diaye AT, Bleikamp S, Feibelman PJ, Michely T (2006) Phys Rev Lett 97(21):215501

21. Gamo Y, Nagashima A, Wakabayashi M, Terai M, Oshima C (1997) Surf Sci 374(1-3):61

22. Mchenry ME, Majetich SA, Artman JO, Degraef M, Staley SW (1994) Phys Rev B 49(16):11358

23. Saito Y, Yoshikawa T, Okuda M, Fujimoto N, Yamamuro S, Wakoh K, Sumiyama K, Suzuki K, Kasuya A, Nishina Y (1993) Chem Phys Lett 212(3-4):379

24. Sun XC, Nava N (2002) Nano Lett 2(7):765

25. Jiao J, Seraphin S (1998) J Appl Phys 83(5):2442

26. Ouyang G, Tan X, Wang CX, Yang GW (2006) Nanotechnology 17(16):4257

27. Dai QQ, Wang YN, Li XB, Zhang Y, Pellegrino DJ, Zhao MX, Zou B, Seo J, Wang YD, Yu WW (2009) ACS Nano 3(6):1518

28. Yasuda H, Mori H (2002) J Cryst Growth 237:234

29. Straumal BB, Mazilkin AA, Protasova SG, Myatiev AA, Straumal PB, Baretzky B (2008) Acta Mater 56(20):6246

30. Sutter E, Sutter P (2008) Nano Lett 8(2):411

31. Sutter EA, Sutter PW (2010) ACS Nano 4(8):4943

32. Yasuda H, Mori H (1992) Phys Rev Lett 69(26):3747

33. Lee JG, Mori H (2004) Phys Rev Lett 93(23):235501

34. Moisala A, Nasibulin AG, Kauppinen EI (2003) J Phys Condens Matter 15(42):S3011

35. Harutyunyan AR, Awasthi N, Jiang A, Setyawan W, Mora E, Tokune T, Bolton K, Curtarolo S (2008) Phys Rev Lett 100(19): 195502

36. Guisbiers G (2010) Nanoscale Res Lett 5(7):1132

37. Qi WH, Wang MP (2004) J Mater Sci 39(7):2529. doi:10.1023/ B:JMSC.0000020020.60857.6a

38. Shandiz MA (2008) J Phys Condens Matter 20(32):325237

39. Sun CQ (2007) Prog Solid State Chem 35(1):1

40. Sun CQ, Wang Y, Tay BK, Li S, Huang H, Zhang YB (2002) J Phys Chem B 106(41):10701

41. Yang CC, Li S (2007) Phys Rev B 75 (16): 165413

42. Ruffino F, Grimaldi MG, Giannazzo F, Roccaforte F, Raineri V (2008) Nanoscale Res Lett 3(11):454

43. Sutter E, Sutter P, Zhu Y (2006) Surf Sci 600(18):3654

44. Sutter PW, Sutter EA (2007) Nat Mater 6(5):363

45. Ostwald W (1990) Z Phys Chem (Leipzig) 34:495

46. Akita T, Tanaka K, Kohyama M (2008) J Mater Sci 43(11):3917. doi:10.1007/s10853-007-2401-4

47. Teranishi T, Hasegawa S, Shimizu T, Miyake M (2001) Adv Mater 13(22): 1699

48. Mclellan RB (1969) Scr Metall Mater 3(6):389

49. Mathieu G, Guiot S, Cabane J (1973) Scr Metall Mater 7(4):421

50. Goldstein AN, Echer CM, Alivisatos AP (1992) Science 256(5062): 1425

51. Chiu HW, Kauzlarich SM, Sutter E (2006) Langmuir 22(12): 5455

52. Emrick RM (1961) Phys Rev 122(6):1720

53. Westmacott KH, Perez MI (1979) J Nucl Mater 83(1):231

54. Sutter E, Sutter P (2006) Adv Mater 18(19):2583

55. Bluhm H, Havecker M, Knop-Gericke A, Kleimenov E, Schlogl R, Teschner D, Bukhtiyarov VI, Ogletree DF, Salmeron M (2004) J Phys Chem B 108(38): 14340

56. Blume R, Havecker M, Zafeiratos S, Teschner D, Vass E, Schnorch P, Knop-Gericke A, Schlogl R, Lizzit S, Dudin P, Barinov A, Kiskinova M (2007) Phys Chem Chem Phys 9(27):3648

57. Johnson AD, Daley SP, Utz AL, Ceyer ST (1992) Science 257(5067):223

58. Teschner D, Borsodi J, Wootsch A, Revay Z, Havecker M, KnopGericke A, Jackson SD, Schlogl R (2008) Science 320(5872):86 